\title{
Plant micro RNAs can control cancer genes expression through a sequence-specific targeting mechanism: the case of MALAT1 and NEAT1
}

\author{
Flaviana Marzano', Mariano Francesco Caratozzolo', Arianna Consiglio², Flavio Licciulli², Sabino Liuni², \\ Elisabetta Sbisà${ }^{2}$, Domenica D'Elia ${ }^{2 \bowtie}$, Apollonia Tullo', Domenico Catalano ${ }^{2}$ \\ ${ }^{1}$ Institute of Biomembranes, Bioenergetics and Molecular Biotechnologies, National Research Council, Bari, Italy \\ ${ }^{2}$ Institute for Biomedical Technologies, National Research Council, Bari, Italy \\ Competing interests: FM none; MFC none; AC none; FL none; SL none; ES none; DD none; AT none; DC none
}

It is well known that some plant compounds, or phytochemicals, can positively affect human health by reducing inflammation and oxidative stress (Issa et al., 2006; Dell'Agli et al., 2013). Although the large number of works published, the molecular mechanisms through which plants can impact human health are still unclear. Recent studies suggest that plant nutrients control the expression of human genes by DNA methylation and histone modifications (Choi and Friso, 2010; Tollefsbol 2014). Moreover, some plant/food-derived microRNAs (miRNAs) accumulate in the sera and tissues of various animals and regulate their gene expression in a sequencespecific manner (Zhang et al., 2012; García-Segura et al., 2013).

We performed a study using a combined in silico and experimental approach to investigate the potential effects and elucidate the molecular mechanisms of edible plant miRNAs on the expression of human genes involved in cancer onset and progression (Marzano et al., 2020). This study demonstrates that plant miRNAs can bind human transcripts in a sequence-specific manner and that their binding is functional. In particular, we have shown that the plant mtr-miR-5754 and gma-miR-4995 directly target the tumour-associated long non-coding RNAs MALAT1 and NEAT1, respectively, in a sequence-specific manner, thus reducing cancer cell proliferation. For the first time, we provide evidence that plant miRNAs can also target human regulatory ncRNAs. These findings open the way to new biotechnological applications in human nutrition and chronic diseases prevention.

\section{Acknowledgements}

This work was supported by the National Research Council (CNR) MIUR Flagship Project InterOmics.

\section{References}

1. Choi SW, Friso S (2010) Epigenetics: A New Bridge between Nutrition and Health, Advances in Nutrition 1(1):8-16. http://! dx.doi.org/10.3945/an.110.1004

2. Dell'Agli $\mathrm{M}$ et al. (2013) Plant food supplements with antiinflammatory properties: a systematic review. Crit Rev Food Sci Nutr 53(4):403-13. http://dx.doi.org/10.1080/10408398.2012.682 123

3. García-Segura L, Pérez-Andrade M, Miranda-Ríos J. (2013) The Emerging Role of MicroRNAs in the Regulation of Gene Expression by Nutrients. J Nutrigenet Nutrigenomics 6:16-31. http://dx.doi.org/10.1159/000345826

4. Issa AY, Volate SR, Wargovich MJ (2006) The role of phytochemicals in inhibition of cancer and inflammation: New directions and perspectives. Journal of Food Composition and Analysis 19:405-419. http://dx.doi.org/10.1016/j.jfca.2006.02.009

5. Marzano F et al. (2020) Plant miRNAs reduce cancer cell proliferation by targeting MALAT1 and NEAT1: a beneficial cross-kingdom interaction. Frontiers in Genetics 11:552490. http://dx.doi.org/10.3389/fgene.2020.552490

6. Tollefsbol TO (2014) Dietary Epigenetics in Cancer and Aging. Cancer Treat Res. 159. http://dx.doi.org/10.1007/978-3-642$38007-5-15$

7. Zhang L et al. (2012) Exogenous plant MIR168a specifically targets mammalian LDLRAP1: evidence of cross-kingdom regulation by microRNA. Cell Res. 22(1):107-26. http://dx.doi. org/10.1038/cr.2011.158 